\title{
TINGKAT KOMPETENSI ANDRAGOGIK LULUSAN PROGRAM STUDI S1 AGRIBISNIS UNIVERSITAS TERBUKA
}

\author{
Nurul Huda (nurul@mail.ut.ac.id) \\ Program Studi Agribisnis, Universitas Terbuka
}

\begin{abstract}
Agricultural extension workers must have several competencies in order to do their job properly. One essential competence to master was related to their andragogic abilities, especially in mastering the concepts of extension and adult education. This research was intended to identify the andragogic competence of agricultural extension workers graduated from Universitas Terbuka (UT). The information of competence aspects such as knowledge, affective, and psychomotor were also collected to elaborate the findings. By using an explanatory research design, a survey technique was implemented among 111 agricultural extension workers who were graduated from UT in four different locations, namely Serang, Karawang, Cirebon, and Tanggamus. Data were collected by using questionnaire and analyzed by using descriptive statistics. In depth interview was also conducted to elaborate the findings. The findings indicated that agricultural extension workers graduated from UT generally had a medium level in their andragogic competence, either in implementing the concepts of extention or in adult education. Their level of knowledge and psychomotor was low, while their affective level were moderate.
\end{abstract}

Keywords: agricultural extension workers, andragogic competence, distance education

Keberhasilan pembangunan pertanian tidak lepas dari peran penyuluh dalam melaksanakan kegiatan penyuluhan pertanian. Sesuai dengan paradigma baru penyuluhan, yang bergeser dari pola top down menjadi bottom up dimana bentuk hubungan antara penyuluh dan petani tidak lagi sebagai atasan dan bawahan, tetapi sebagai mitra sejajar petani, maka tugas pokok dan fungsi penyuluh juga mengalami perubahan ke arah perannya sebagai mitra sejajar petani. Kondisi ini menuntut penyuluh untuk selalu mengembangkan diri agar dapat memberikan layanan yang memuaskan petani.

Untuk dapat melaksanakan tugas pokok dan fungsi dengan baik, penyuluh harus memiliki kompetensi tertentu. Pengembangan kompetensi tersebut perlu disesuaikan dengan kondisi dan tantangan penyuluhan saat ini, perkembangan ilmu pengetahuan dan teknologi (IPTEK), serta adanya arus globalisasi yang menuntut daya saing tinggi sehingga dibutuhkan sumber daya manusia yang berkualitas. Kini ada Undang-undang Nomor 16 tahun 2006 tentang sistem penyuluhan pertanian yang mendukung peningkatan kompetensi penyuluh.

Namun demikian, hasil penelitian Suryaman (2001) menunjukkan bahwa tingkat kompetensi dan kinerja penyuluh di provinsi NTB, NTT, Jatim, dan Jabar masih tergolong rendah. Puspadi (2002) mengungkap bahwa tingkat kompetensi penyuluh pertanian di tiga provinsi yaitu Lampung, Jawa 
Timur, dan Nusa Tenggara Barat, berada pada kategori sedang. Hasil penelitian lain yang dilakukan oleh Marius (2007) di Nusa Tenggara Timur dan Gatut (2008) di Jawa Barat juga menunjukkan bahwa kompetensi penyuluh dinilai masih rendah. Dari beberapa hasil penelitian tersebut, dapat dikatakan bahwa tingkat kompetensi penyuluh masih tergolong rendah sehingga dapat berdampak pada kurangnya kualitas layanan penyuluh dalam kegiatan penyuluhan (Sisdiknas).

Mengacu pada Undang-undang No. 20 tahun 2003 tentang Sistem Pendidikan Nasional

Salah satu kompetensi yang perlu dimiliki seorang penyuluh sebagai pendidik atau guru adalah kompetensi andragogik, yaitu kemampuan penyuluh dalam hal pembelajaran orang dewasa. Penyuluh yang memiliki kompetensi tersebut diharapkan dapat menghasilkan kinerja yang baik sesuai dengan tuntutan tugasnya sebagai penyuluh. Kompetensi merupakan karakteristik mendasar yang menentukan pencapaian hasil kerja sehingga tingkat kompetensi seseorang dapat digunakan untuk memprediksi hasil kerja yang akan dihasilkan. Dengan demikian, informasi atau penelitian tentang tingkat kompetensi andragogik yang dimiliki penyuluh merupakan faktor penting.

Kompetensi andragogik penyuluh dapat diperoleh melalui proses belajar, salah satunya melalui pendidikan di program studi S1 Penyuluhan dan Komunikasi Pertanian Universitas Terbuka (PKP-UT) yang sekarang berdasarkan kodifikasi program studi Dikti menjadi Program Studi Agribisnis bidang minat PKP-UT. Kompetensi tersebut diperoleh melalui mata kuliah-mata kuliah yang mendukung pencapaian kompetensi yang diharapkan. Sesuai dengan karakteristiknya sebagai perguruan tinggi jarak jauh, UT memberikan pembelajaran melalui media yaitu bahan ajar cetak (modul) dan non cetak (web suplemen, audio, video, dan CAI). Sebagai pendukung proses pembelajaran, UT juga memberikan praktikum, praktek kerja lapang, maupun tutorial. Sedangkan evaluasi belajar dilakukan dalam bentuk tugas tutorial, praktek/ujian praktikum, ujian akhir semester (UAS), maupun tugas akhir program (TAP).

Penelitian ini bertujuan untuk: (1) mengidentifikasi tingkat kompetensi andragogik penyuluh Iulusan UT dan aspek-aspeknya (pengetahuan, sikap mental, dan keterampilan); serta (2) mengidentifikasi persepsi stakeholders (pemangkujabatan) terhadap kompetensi andragogik penyuluh lulusan UT.

\section{METODOLOGI}

Penelitian ini merupakan explanatory research yang berupaya menjelaskan fenomena kompetensi andragogik penyuluh alumni UT di wilayah Serang, Karawang, Cirebon, dan Tanggamus. Untuk memperkaya hasil penelitian, stakeholders (pemangkujabatan), yaitu petani dan sejawat penyuluh juga digunakan sebagai responden untuk melengkapi informasi serta mempertajam analisis data kuantitatif yang ada.

Populasi dalam penelitian ini adalah semua penyuluh alumni UT di wilayah Serang, Karawang, Cirebon, dan Tanggamus. Responden diambil dari seluruh populasi dengan menggunakan metode sensus. Responden penyuluh diambil dari data penyuluh yang menjadi alumni Program Studi S1 Penyuluhan dan Komunikasi Pertanian FMIPA-UT. Dari 112 responden penelitian, 1 (satu) orang di keluarkan dari data karena walaupun yang bersangkutan merupakan alumni S1 PKP-UT, tetapi tidak melaksanakan kegiatan penyuluhan kepada petani karena bekerja sebagai petugas statistik di BIPP Serang, sehingga jumlah responden berkurang menjadi 111 orang.

Pengumpulan data dilakukan melalui survey dengan menggunakan kuesioner. Kuesioner dikembangkan berdasarkan indikator-indikator kompetensi andragogik penyuluh. Hasil uji coba 
kuesioner menunjukkan bahwa rata-rata nilai keterhandalan (reliabilitas) kuesioner berkisar antara 0,6 sampai 0,9. Item kuesioner yang mempunyai nilai reliabilitas dibawah 0,6 direvisi hingga item tersebut mengukur kompetensi yang diharapkan. Kuesioner terdiri atas pertanyaan tertutup dan terbuka. Berdasarkan kuesioner tertutup dihasilkan data kuantitatif yang selanjutnya dianalisis menggunakan statistik deskriptif. Sedangkan dengan kuesioner terbuka dihasilkan informasi kualitatif, yang berfungsi melengkapi informasi serta mempertajam analisis data kuantitatif yang ada. Data yang diperoleh diolah dengan menggunakan SPSS versi 15.0, dan dianalisis sesuai dengan tujuan penelitian yaitu analisis deskriptif.

\section{HASIL DAN PEMBAHASAN}

Pembahasan dalam tulisan ini diurutkan sesuai dengan tujuan penelitian yaitu tingkat kompetensi andragogik penyuluh lulusan UT, aspek kompetensi (pengetahuan, sikap mental, dan keterampilan) andragogik penyuluh lulusan UT, dan persepsi stakeholders terhadap kompetensi andragogik penyuluh lulusan UT.

\section{Tingkat Kompetensi Andragogik Penyuluh Alumni UT dan Aspek-aspeknya}

Kompetensi andragogik penyuluh alumni UT mencakup kemampuan dalam penerapan konsep penyuluhan dan pendidikan orang dewasa. Secara umum, tingkat kompetensi andragogik penyuluh dalam aspek pengetahuan, sikap mental, dan keterampilannya disajikan pada Tabel 1 ,

Tabel 1 Sebaran penyuluh alumni UT menurut tingkat kompetensi andragogik dan aspek kompetensi $(n=111)$

\begin{tabular}{|c|c|c|c|c|c|c|c|c|c|}
\hline \multirow{3}{*}{ Sub Peubah } & \multirow{3}{*}{ kategori } & \multicolumn{6}{|c|}{ Aspek kompetensi } & \multirow{2}{*}{\multicolumn{2}{|c|}{ Keseluruhan }} \\
\hline & & \multicolumn{2}{|c|}{ Pengetahuan } & \multicolumn{2}{|c|}{ Sikap mental } & \multicolumn{2}{|c|}{ keterampilan } & & \\
\hline & & $\mathrm{n}$ & $\%$ & $n$ & $\%$ & $\mathrm{n}$ & $\%$ & $\mathrm{n}$ & $\%$ \\
\hline \multirow{3}{*}{$\begin{array}{l}\text { Penguasaan } \\
\text { Konsep } \\
\text { penyuluhan }\end{array}$} & Rendah & 106 & 95,5 & 1 & 0,9 & 59 & 53,2 & 21 & 18,9 \\
\hline & Sedang & 4 & 3,6 & 23 & 20,7 & 42 & 37,8 & 87 & 78,4 \\
\hline & Tinggi & 1 & 0,9 & 87 & 78,4 & 10 & 9,0 & 3 & 2,7 \\
\hline \multirow{3}{*}{$\begin{array}{l}\text { Penguasaan } \\
\text { tentang prinsip } \\
\text { belajar orang } \\
\text { dewasa }\end{array}$} & Rendah & 104 & 93,7 & 1 & 0,9 & 87 & 78,4 & 23 & 20,7 \\
\hline & Sedang & 6 & 5,4 & 49 & 44,1 & 23 & 20,7 & 88 & 79,3 \\
\hline & Tinggi & 1 & 0,9 & 61 & 55,0 & 1 & 0,9 & 0 & 0 \\
\hline \multirow[t]{3}{*}{ Total Andragogik } & Rendah & 102 & 91,9 & 1 & 0,9 & 77 & 69,4 & 14 & 12,6 \\
\hline & Sedang & 8 & 7,2 & 37 & 33,3 & 31 & 27,9 & 95 & 85,6 \\
\hline & Tinggi & 1 & 0,9 & 73 & 65,8 & 3 & 2,7 & 2 & 1,8 \\
\hline
\end{tabular}

sedangkan sebaran rataan skor kompetensi andragogik penyuluh alumni UT berdasarkan aspekaspeknya disajikan pada Tabel 2.

Pada Tabel 1 diketahui bahwa tingkat kompetensi andragogik penyuluh alumni UT tergolong sedang. Hal ini disebabkan belum optimalnya kemampuan penyuluh dalam penerapan konsep 
penyuluhan dan pendidikan orang dewasa. Kondisi ini menunjukkan bahwa perlu adanya upaya peningkatan kompetensi andragogik penyuluh alumni UT yang difokuskan pada peningkatan kemampuan penyuluh dalam penerapan konsep penyuluhan dan pendidikan orang dewasa.

Secara umum, tingkat kompetensi andragogik penyuluh yang tergolong sedang (85,6 persen) dapat dilihat pada Gambar 1. Dari gambar tersebut dapat dikatakan bahwa tingkat kompetensi andragogik penyuluh lulusan UT belum optimal dan perlu ditingkatkan lagi agar penyuluh dapat memiliki kemampuan dalam pembelajaran orang dewasa yang lebih baik.

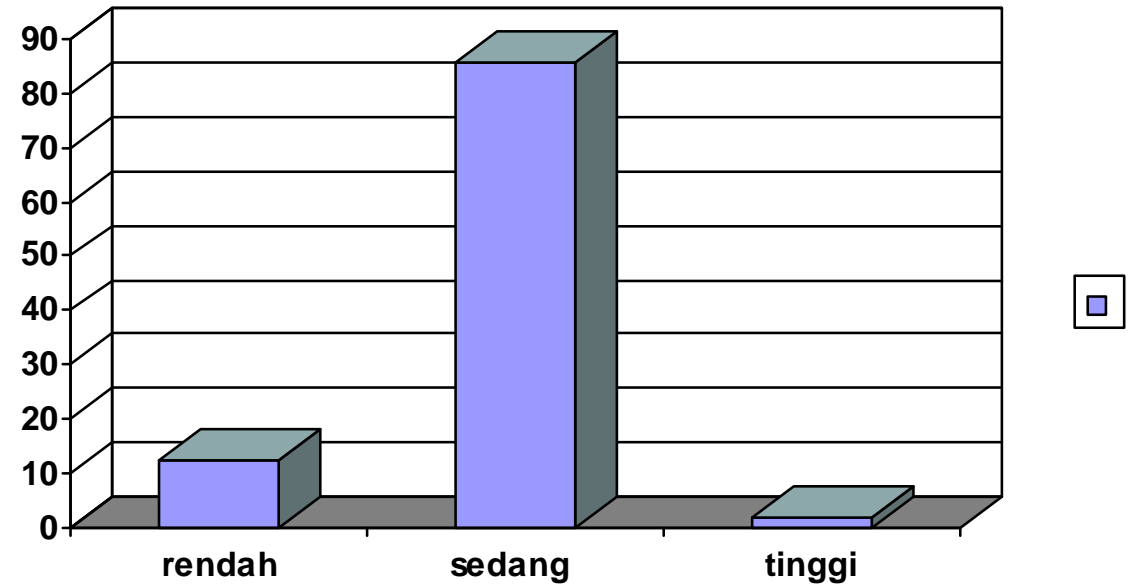

Gambar 1. Tingkat kompetensi andragogik penyuluh alumni UT

Tingkat kompetensi andragogik penyuluh alumni UT yang tergolong sedang dengan rataan skor 63 (Tabel 2), ditunjukkan oleh sikap mentalnya, namun pengetahuan dan keterampilannya tergolong rendah. Hal ini menunjukkan bahwa walaupun penyuluh alumni UT mempunyai pemahaman dan tindakan yang rendah, namun memiliki sikap yang cukup positif tentang kemampuan andragogik yang harus dimiliki seorang penyuluh, khususnya yang berkaitan dengan penerapan konsep penyuluhan dan prinsip belajar orang dewasa. Untuk itu, upaya peningkatan kompetensi andragogik penyuluh dapat difokuskan pada peningkatan pengetahuan dan keterampilannya.

Tabel 2. Sebaran Rataan Skor Kompetensi Andragogik Penyuluh Alumni UT

\begin{tabular}{|c|c|c|c|c|c|c|c|c|c|}
\hline \multirow{3}{*}{$\begin{array}{l}\text { Jenis } \\
\text { Kompetensi }\end{array}$} & \multirow{3}{*}{$\begin{array}{l}\text { Sub } \\
\text { kompetensi }\end{array}$} & \multicolumn{6}{|c|}{ Aspek Kompetensi } & \multirow{2}{*}{\multicolumn{2}{|c|}{$\begin{array}{c}\text { Keseluruhan } \\
\text { Aspek Kompetensi }\end{array}$}} \\
\hline & & \multicolumn{2}{|c|}{ Pengetahuan } & \multicolumn{2}{|c|}{ Sikap Mental } & \multicolumn{2}{|c|}{ Keterampilan } & & \\
\hline & & rataan & $\mathrm{sd}$ & rataan & $\mathrm{sd}$ & rataan & $\mathrm{sd}$ & rataan & $\mathrm{sd}$ \\
\hline \multirow[t]{3}{*}{ Andragogik } & $\begin{array}{l}\text { Konsep } \\
\text { penyuluhan }\end{array}$ & 50 & 7 & 85 & 14 & 49 & 20 & 65 & 14 \\
\hline & $\begin{array}{l}\text { Prinsip belajar } \\
\text { orang dewasa }\end{array}$ & 49 & 7 & 82 & 16 & 38 & 14 & 61 & 12 \\
\hline & $\begin{array}{l}\text { Total } \\
\text { Andragogik }\end{array}$ & 50 & 7 & 84 & 14 & 43 & 15 & 63 & 12 \\
\hline
\end{tabular}

Secara rinci, tingkat kompetensi andragogik penyuluh lulusan UT dapat dilihat dari kemampuannya dalam penguasaan konsep penyuluhan dan prinsip pembelajaran orang dewasa. 


\section{Kompetensi Penyuluh dalam Penguasaan Konsep Penyuluhan}

Pada Tabel 1 diketahui bahwa tingkat kompetensi penyuluh alumni UT dalam penguasaan konsep penyuluhan tergolong sedang, yang disebabkan oleh masih belum optimalnya pemahaman penyuluh tentang konsep penyuluhan yaitu bahwa penyuluhan bertujuan untuk meningkatkan pengetahuan, sikap dan keterampilan petani; serta untuk membantu petani agar mampu menolong dirinya sendiri. Kondisi ini menunjukkan bahwa perlu adanya upaya peningkatan kemampuan penyuluh alumni UT dalam penguasaan konsep penyuluhan yang difokuskan pada pemahamannya tentang penyuluhan yang bertujuan untuk meningkatkan pengetahuan, sikap dan keterampilan petani; serta untuk membantu petani agar mampu menolong dirinya sendiri.

Kompetensi penyuluh alumni UT dalam menerapkan konsep penyuluhan tergolong sedang (Tabel 1). Tingkat pengetahuan penyuluh alumni UT tentang konsep penyuluhan tergolong rendah, demikian juga dengan keterampilannya. Namun penyuluh alumni UT memiliki keyakinan tentang konsep penyuluhan yang tinggi. Hal ini menunjukkan bahwa penyuluh alumni UT belum sepenuhnya memahami bahwa penyuluhan bertujuan untuk meningkatkan pengetahuan, sikap dan keterampilan petani; dan untuk membantu petani agar mampu menolong dirinya sendiri. Disamping itu, hal-hal tersebut belum diterapkan dengan baik sebagai tindakan. Namun demikian, penyuluh alumni UT memiliki sikap yang sangat positif terhadap penerapan konsep penyuluhan dan pembelajaran orang dewasa. Untuk itu, upaya peningkatan kompetensi penyuluh dalam penguasaan konsep penyuluhan dapat difokuskan pada peningkatan pengetahuan dan keterampilannya.

\section{Kompetensi Penyuluh dalam Penguasaan Prinsip Belajar Orang Dewasa}

Tingkat kompetensi penyuluh alumni UT dalam penguasaan prinsip belajar orang dewasa tergolong sedang, yang disebabkan oleh masih belum optimalnya penguasaan penyuluh tentang prinsip belajar orang dewasa yaitu partisipatif, kemitraan, dan pemberdayaan. Kondisi ini menunjukkan bahwa perlu adanya upaya peningkatan kemampuan penyuluh alumni UT dalam penguasaan prinsip belajar orang dewasa yang difokuskan pada penguasaannya tentang prinsip belajar orang dewasa yaitu partisipatif, kemitraan, dan pemberdayaan.

Kompetensi penyuluh alumni UT dalam menerapkan prinsip belajar orang dewasa yang tergolong sedang (Tabel 1), ditunjukkan oleh pengetahuan dan tindakannya yang tergolong rendah. Namun penyuluh alumni UT memiliki keyakinan yang tinggi tentang prinsip belajar orang dewasa. Hal ini menunjukkan bahwa penyuluh alumni UT belum mempunyai pemahaman yang memadai tentang prinsip belajar orang dewasa, yaitu prinsip partisipatif, kemitraan, dan pemberdayaan. Walaupun prinsip tersebut belum diterapkan dengan baik sebagai tindakan, namun penyuluh alumni UT mempunyai sikap yang sangat positif terhadap prinsip partisipatif, kemitraan, dan pemberdayaan dalam kegiatan penyuluhan. Untuk itu, upaya peningkatan kompetensi penyuluh dalam penguasaan prinsip belajar orang dewasa dapat difokuskan pada peningkatan pengetahuan dan keterampilannya.

Dari hasil wawancara mendalam dengan penyuluh alumni UT dapat diketahui bahwa walaupun penyuluh memiliki pemahaman yang cukup tentang konsep pembelajaran orang dewasa, namun karena pengetahuan tersebut belum seluruhnya dikuasai dengan baik, penyuluh masih menemui kesulitan dalam menerapkannya sebagai tindakan.

Dari paparan tersebut diatas, dapat dikatakan bahwa upaya peningkatan kompetensi andragogik penyuluh dapat difokuskan pada peningkatan pengetahuan dan keterampilan andragogiknya, khususnya dalam penguasaan konsep penyuluhan dan pembelajaran orang dewasa. 


\section{Tingkat Kompetensi Andragogik Penyuluh Alumni UT menurut Persepsi Penyuluh,} Sejawat, dan Petani.

Kompetensi penyuluh dapat diukur sudut pandang stakeholders, baik dari persepsi penyuluh itu sendiri, persepsi petani sebagai pihak yang mendapat layanan penyuluh dalam kegiatan penyuluhan, maupun persepsi penyuluh lain yang menjadi rekan sejawat. Secara umum, nilai rataan kompetensi penyuluh dari persepsi petani adalah lebih rendah dibandingkan dengan nilai rataan dari persepsi penyuluh dan sejawat (Tabel 3).

Tabel 3. Perbandingan nilai rataan kompetensi andragogik menurut persepsi penyuluh, petani, dan sejawat

\begin{tabular}{llccc}
\hline Jenis & Aspek & \multicolumn{3}{c}{ Persepsi } \\
\cline { 3 - 5 } kompetensi & kompetensi & $\begin{array}{c}\text { Penyuluh } \\
(\mathrm{n}=6)\end{array}$ & $\begin{array}{c}\text { Petani } \\
(\mathrm{n}=12)\end{array}$ & $\begin{array}{c}\text { Sejawat penyuluh } \\
(\mathrm{n}=12)\end{array}$ \\
\hline Andragogik & Pengetahuan & 48,6 & 50,4 & 58,3 \\
& Sikap & 80,6 & 72,2 & 76,9 \\
& Keterampilan & 40,7 & 40,7 & 49,1 \\
& Keseluruhan & 56,6 & 54,5 & 61,4 \\
\hline Kompetensi keseluruhan & $\mathbf{6 0 , 7}$ & $\mathbf{5 8 , 5}$ & $\mathbf{6 2 , 6}$ \\
\hline
\end{tabular}

Hal ini berarti petani menilai kemampuan andragogik penyuluh alumni UT lebih rendah dibandingkan dengan penilaian penyuluh dan sejawat penyuluh itu sendiri. Dengan kata lain ada indikasi ketidakpuasan petani terhadap kemampuan penyuluh tersebut. Untuk itu, agar petani yang merupakan sasaran penyuluhan mendapatkan layanan yang memuaskan, perlu adanya upaya peningkatan kompetensi andragogik penyuluh alumni UT.

Nilai rataan kompetensi andragogik menurut persepsi petani tergolong lebih rendah pada aspek sikap dibandingkan dengan persepsi penyuluh alumni UT dan sejawatnya. Hal ini berarti petani menilai minat penyuluh alumni UT terhadap pembelajaran orang dewasa masih belum optimal. Untuk itu, agar petani yang merupakan sasaran penyuluhan mendapatkan layanan yang memuaskan, perlu adanya upaya pengembangan sikap penyuluh alumni UT dalam pembelajaran orang dewasa, khususnya dalam hal pemahaman konsep penyuluhan dan prinsip belajar orang dewasa.

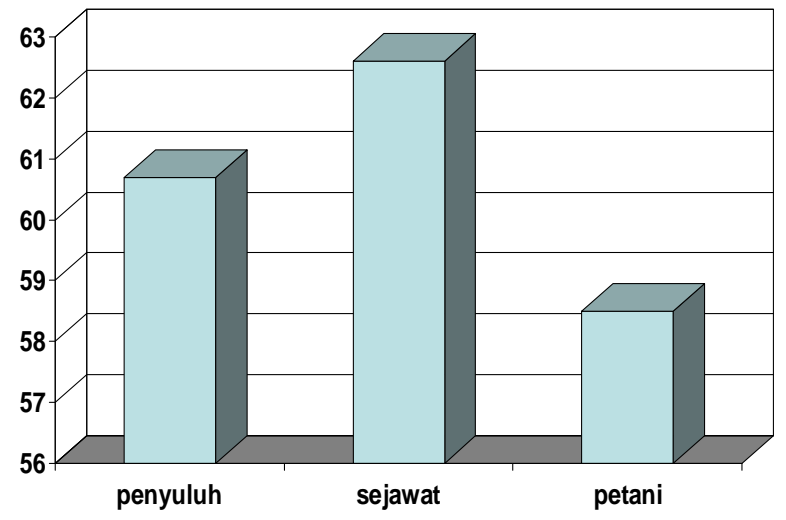

Gambar 2. Perbandingan nilai rataan kompetensi andragogik menurut persepsi penyuluh, sejawat, dan petani. 
Secara umum, berdasarkan Tabel 3 dapat digambarkan perbandingan nilai rataan kompetensi andragogik penyuluh alumni UT menurut persepsi penyuluh itu sendiri, petani sebagai pihak yang menerima layanan penyuluh, dan rekan sejawat penyuluh seperti yang disajikan pada Gambar 2.

Pada Gambar 1 dapat dilihat bahwa penyuluh itu sendiri dan sejawatnya menilai kompetensi andragogik penyuluh relatif lebih tinggi dari penilaian petani. Hal ini menunjukkan adanya ketidakpuasan petani sebagai pihak yang menerima layanan penyuluh. Oleh karena itu, agar petani dapat lebih merasakan manfaat kegiatan penyuluhan yang diberikan, penyuluh perlu memahami perilaku petani yaitu dengan cara meningkatkan interaksi penyuluh dengan petani. Hal tersebut dapat dilakukan dengan melakukan pendekatan partisipatif kepada petani dalam setiap tahapan kegiatan penyuluhan.

Tingkat kompetensi andragogik penyuluh berdasarkan aspek-aspeknya secara umum tergolong sedang, baik dipandang dari persepsi penyuluh, petani, dan sejawat. Namun demikian, baik penyuluh, petani, dan sejawat menganggap tingkat pengetahuan dan keterampilan andragogik penyuluh masih rendah. Hal ini berarti baik penyuluh, petani, dan sejawat menganggap tingkat pengetahuan dan keterampilan andragogik penyuluh masih belum optimal. Oleh karena itu, perlu adanya perbaikan dan peningkatan pengetahuan dan keterampilan penyuluh yang berkaitan dengan pembelajaran orang dewasa, khususnya dalam pemahaman terhadap konsep penyuluhan dan prinsip belajar orang dewasa.

Tabel 5. Perbandingan Tingkat Kompetensi Andragogik Menurut Persepsi Penyuluh, Petani, dan Sejawat.

\begin{tabular}{|c|c|c|c|c|c|c|c|c|}
\hline \multirow{3}{*}{$\begin{array}{l}\text { Dimensi } \\
\text { kompetensi }\end{array}$} & \multirow[t]{3}{*}{ Aspek kompetensi } & \multirow[t]{3}{*}{ Kategori } & \multicolumn{6}{|c|}{ Persepsi } \\
\hline & & & \multicolumn{2}{|c|}{$\begin{array}{l}\text { Penyuluh } \\
(n=6)\end{array}$} & \multicolumn{2}{|c|}{$\begin{array}{l}\text { Petani } \\
(n=12)\end{array}$} & \multicolumn{2}{|c|}{$\begin{array}{l}\text { Sejawat penyuluh } \\
\qquad(n=12)\end{array}$} \\
\hline & & & $\mathrm{n}$ & $\%$ & $\mathrm{n}$ & $\%$ & $n$ & $\%$ \\
\hline \multirow[t]{12}{*}{ Andragogik } & \multirow[t]{3}{*}{ Pengetahuan } & Rendah & 6 & 100,0 & 10 & 83,3 & 6 & 50,0 \\
\hline & & Sedang & 0 & 0 & 2 & 16,7 & 6 & 50,0 \\
\hline & & Tinggi & 0 & 0 & 0 & 0 & 0 & 0 \\
\hline & \multirow[t]{3}{*}{ Sikap mental } & Rendah & 0 & 0 & 2 & 16,7 & 0 & 0 \\
\hline & & Sedang & 2 & 33,3 & 4 & 33,3 & 4 & 33,3 \\
\hline & & Tinggi & 4 & 66,7 & 6 & 50,0 & 8 & 66,7 \\
\hline & \multirow[t]{3}{*}{ Keterampilan } & Rendah & 4 & 66,7 & 8 & 66,7 & 5 & 41,7 \\
\hline & & Sedang & 2 & 33,3 & 4 & 33,3 & 7 & 58,3 \\
\hline & & Tinggi & 0 & 0 & 0 & 0 & 0 & 0 \\
\hline & \multirow[t]{3}{*}{ Total Andragogik } & Rendah & 0 & 0 & 1 & 8,3 & 0 & 0 \\
\hline & & Sedang & 6 & 100,0 & 11 & 91,7 & 12 & 100,0 \\
\hline & & Tinggi & 0 & 0 & 0 & 0 & 0 & 0 \\
\hline
\end{tabular}

Keterangan : rendah (skor 0-50), sedang (skor 51-75), tinggi (skor 76-100)

Dari hasil wawancara mendalam, dapat diketahui bahwa petani memang menilai kompetensi andragogik penyuluh lulusan UT masih perlu ditingkatkan lagi. Hal ini disebabkan penyuluh belum bisa memberdayakan petani atau membantu petani untuk menolong dirinya sendiri secara utuh sesuai konsep penyuluhan. Hal berbeda ditunjukkan oleh sejawat yang menilai tingkat kompetensi andragogik penyuluh alumni UT baik. Hal ini disebabkan penyuluh alumni UT yang masa kerjanya rata-rata sudah lama mempunyai pengalaman yang cukup tentang penyuluhan, khususnya yang berkaitan dengan konsep penyuluhan dan pembelajaran orang dewasa. 
Secara umum, dari paparan di atas dapat disimpulkan bahwa stakeholders (petani dan sejawat penyuluh) menunjukkan penilaian yang berbeda tentang kompetensi andragogik penyuluh alumni UT. Dibandingkan dengan persepsi penyuluh alumi UT dan sejawat penyuluh, petani menilai kompetensi andragogik penyuluh tergolong lebih rendah. Maknanya, ada ketidakpuasan petani terhadap kompetensi yang dimiliki penyuluh. Kondisi ini disebabkan kompetensi yang dimiliki penyuluh lebih mengarah pada tugas yang diberikan atasan dan kurang mengarah pada kompetensi yang dibutuhkan petani. Hal ini menunjukkan bahwa agar petani mendapatkan layanan yang memuaskan dari penyuluh, perlu adanya perbaikan atau peningkatan kompetensi andragogik penyuluh alumni UT.

\section{KESIMPULAN DAN SARAN}

Dari hasil dan pembahasan di atas, maka kesimpulan yang dapat dirumuskan sesuai dengan tujuan penelitian adalah sebagai berikut; pertama, tingkat kompetensi andragogik penyuluh alumni UT tergolong sedang, baik dalam penguasaan konsep penyuluhan maupun dalam penguasaan prinsip belajar orang dewasa. Aspek kompetensi yang tergolong sedang adalah pengetahuan andragogik. tindakan andragogik, yaitu penerapan konsep penyuluhan dan pembelajaran orang dewasa; dan kedua yaitu petani menilai kompetensi andragogik penyuluh lulusan UT tergolong rendah dan tidak memuaskannya, sedangkan sejawat menilai kompetensi andragogik penyuluh sudah tergolong baik.

Terkait dengan temuan penelitian ini, maka saran yang dapat diberikan adalah sebagai berikut: pertama, mengingat tingkat kompetensi andragogik penyuluh lulusan UT tergolong masih sedang, perlu ada upaya peningkatan kompetensi tersebut yang difokuskan pada peningkatan aspek pengetahuan dan keterampilan andragogik, baik dalam hal penguasaan konsep penyuluhan maupun dalam hal penguasaan prinsip belajar orang dewasa; dan kedua yaitu mengingat petani menilai kompetensi andragogik penyuluh masih tergolong rendah, maka agar petani merasa puas, perlu upaya peningkatan kompetensi andragogik penyuluh lulusan UT.

\section{REFERENSI}

[Deptan] Departemen Pertanian. (2006). Undang-undang RI No 16 tentang “Sistem penyuluhan pertanian, perikanan, dan kehutanan". Departemen Pertanian. Jakarta.

[Depdiknas] Departemen Pendidikan Nasional. (2005). Undang-undang RI No 14 tentang "Guru dan dosen". Departemen Pendidikan Nasional. Jakarta.

Gatut, B, N. (2008). Kompetensi penyuluh sarjana dalam pembangunan pertanian: Kasus di Provinsi Jawa Barat. Disertasi Doktor yang tidak dipublikasikan, Institut Pertamian Bogor.

[Depdiknas] Departemen Pendidikan Nasional. (2003). Undang-undang No. 20 tentang "Sistem pendidikan nasional". Departemen Pendidikan. Jakarta.

Marius, J.A. (2007). "Pengembangan kompetensi penyuluh pertanian di provinsi Nusa Tenggara Timur". Disertasi Doktor yang tidak dipublikasikan, Institut Pertamian Bogor.

Puspadi, K. (2002). "Rekonstruksi Sistem Penyuluhan Pertanian". Disertasi Doktor yang tidak dipublikasikan, Institut Pertamian Bogor.

Suryaman, M. (2001). Kelembagaan dan mekanisme penyuluhan pertanian di kabupaten/kota dalam pelaksanaan otonomi daerah. Jakarta: Pusat Pengkajian SDM Pertanian, Badan Pengembangan SDM Pertanian, Departemen Pertanian.

Huda, N. (2010). Pengembangan kompetensi penyuluh pertanian lulusan pendidikan jarak jauh Universitas Terbuka. Disertasi Doktor Doktor yang tidak dipublikasikan, Institut Pertamian Bogor. 